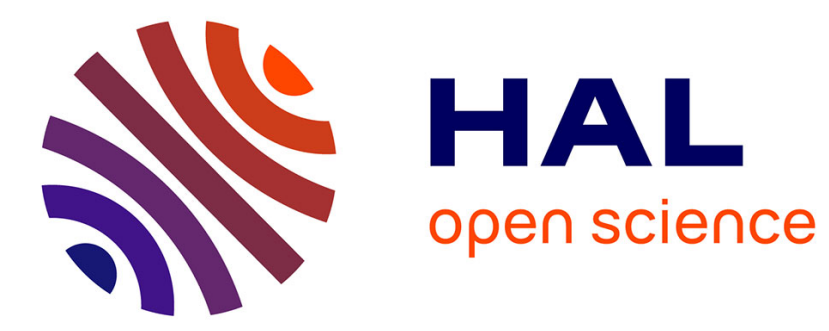

\title{
Orthogonality and Presuppositions. A Bayesian Perspective
}

\author{
Jacques Jayez
}

\section{- To cite this version:}

Jacques Jayez. Orthogonality and Presuppositions. A Bayesian Perspective. 2014. hal-01073511

\section{HAL Id: hal-01073511 \\ https://hal.science/hal-01073511}

Preprint submitted on 9 Oct 2014

HAL is a multi-disciplinary open access archive for the deposit and dissemination of scientific research documents, whether they are published or not. The documents may come from teaching and research institutions in France or abroad, or from public or private research centers.
L'archive ouverte pluridisciplinaire HAL, est destinée au dépôt et à la diffusion de documents scientifiques de niveau recherche, publiés ou non, émanant des établissements d'enseignement et de recherche français ou étrangers, des laboratoires publics ou privés. 


\title{
Orthogonality and Presuppositions. A Bayesian Perspective
}

\author{
Jacques Jayez ${ }^{\star}$ \\ ENS de Lyon and L2C2, CNRS \\ jjayez@isc.cnrs.fr
}

\begin{abstract}
This work focuses on the reasons why the projection properties of presuppositional elements are not uniform. Presupposition projection designates the fact that operators that suspend the truth of a proposition have no effect on the presupposition it is associated with. For instance, with Paul did not stop smoking, the main content (that Paul does not smoke) is canceled by the negation whereas the presupposition that Paul has been smoking is left untouched. It has been observed that projection is not uniform across the different expressions that convey a presupposition (its triggers), and a distinction between weak and strong triggers has emerged. It seems that this distinction correlates with an intuition of (non-) orthogonality, that is, of (non-)independence between the main content and the presupposition. I argue that this intuition is correct to some extent but has to be clarified. To this aim, I propose a Bayesian approach, which provides a more precise rendering of orthogonality.
\end{abstract}

\section{Introduction}

A significant part of the large literature on presuppositions (PP) has been concerned with the phenomenon of projection. Projection denotes the fact that operators like negation, interrogation or if, which normally cancel or suspend the truth of a proposition, have no effect on the PP associated with the proposition. For instance, in Did Paul stop smoking?, the truth of the proposition that Paul smokes is suspended, whereas the PP that Paul has been smoking remains active. The most natural reading of the question is 'Given that Paul has been smoking, is it true or false that he does not smoke now?'. However, in some cases, the PP itself can be suspended and it seems that the possibility of suspending the $\mathrm{PP}$ varies with the different expressions that convey it (its triggers). Recently, this has led to a distinction between weak triggers (or soft triggers), those that allow for suspending the PP, and strong triggers (or hard triggers), which do not. Although this distinction has some empirical support, it is far from transparent. Why should some triggers be 'stronger' than others? It seems that the difference

\footnotetext{
* I am grateful to my two anonymous reviewers for convincing me with excellent arguments to rewrite the initial version of this paper. They are not responsible for the remaining shortcomings.
}

To appear in the Proceedings of the ESSLLI 2013 Workshop on Bayesian Natural Language Semantics and Pragmatics, published by Springer 
depends on the (degree of) orthogonality of the PP and the main content (MC). For instance, in Paul stopped smoking, the MC (Paul does not smoke) and the PP (he has been smoking) seem to be somehow 'entangled', whereas with Paul hit the target too, the MC (Paul hit the target) and the PP (someone else did) seem to be independent ('orthogonal'). In this paper, I show that orthogonality is not exactly what we need and that the difference between weak and strong triggers is amenable to a general principle regulating discourse attachment in a Bayesian framework. In section 2, I recall the main notions and observations that are at the origin of the projection problem. In section 3, I present introspective (3.2) and experimental (3.3) data that seem to support the distinction between weak and strong triggers. I discuss the interpretation of the experimental data in section 3.4, arguing that they are actually based on a metalinguistic interpretation. I turn to orthogonality in section 4. In section 4.1, I present Abbott's take on the weak/strong distinction and argues that her analysis in terms of detachability is misleading. However, I defend her intuition in section 4.2 and show how it can be expressed in a Bayesian framework. Finally, in section 5, I address two remaining problems. Admittedly, the empirical scope of this paper is limited because I do not study the full range of triggers (see section 3.1 for a discussion of this problem). However, one has to start somewhere and I think that is not inconsequential to show that the distinction between weak and strong triggers, which has gained great currency in semantics, has to be reanalyzed.

\section{Presuppositions and projection}

\subsection{Basic notions}

Natural languages offer to speakers the opportunity to convey different types of information in a single utterance. The MC concerns the most basic truthconditional contribution of the utterance, whereas the non-MC concerns, for instance, intellectual or emotional attitudes of the speaker, or what she presupposes to be true. So, (1a) informs the hearer that some friend of the speaker found a solution (MC), but also that this fact was unexpected (intellectual attitude) and that the speaker does not hold the mentioned friend in high regard (emotional attitude). (1b) asserts that Charles has talked to someone (MC) and presupposes that it is his sister.

(1) a. Unexpectedly, my stupid friend found the solution.

b. Charles has talked to his sister.

A quick test to separate $\mathrm{MC}$ and non-MC is to consider what the natural target of a direct refutation is. In most cases, people interpret the target as being the $\mathrm{MC}$, see (2) and (3).

(2) A - Unexpectedly, my stupid friend found the solution.

B - It's false/You're wrong/You're mistaken.

$\rightsquigarrow$ Your friend did not find the solution

$\not \rightarrow$ It's not unexpected or/and your friend is not stupid 
(3) A - Charles has talked to his sister.

B - It's false/You're wrong/You're mistaken.

$\rightsquigarrow$ Charles did not talk to his sister

$\Varangle \rightarrow$ Charles has no sister

Among the expressions conveying a non-MC, presuppositions (PP) have been the subject of intensive research. Intuitively, a PP is a piece of information which is taken for granted or presented as such (Stalnaker, 1974) or must be true in every context where the sentence conveying it can be asserted without contradiction (Heim, 1983; Beaver, 2001). A hallmark of the non-MC is its tendency to project, that is, to remain unaffected by operators that negate or suspend the $\mathrm{MC}$, such as negation, interrogation or if. For instance, whereas the proposition that my friend found the solution does not receive a definite truth-value in (4), the non-MC (my friend is stupid) is endorsed by the speaker exactly as in (1a). A similar difference holds for negation and conditional.

(4) Did my stupid friend find the solution?

$\not \sim$ My friend found the solution

$\rightsquigarrow$ My friend is stupid

\subsection{Ideal and actual projection}

In an ideally simple world, projection would be uniform across all types of triggers. What is the situation in the real world? Non-MC tends to project rather neatly for conventional implicatures (Potts, 2005) such as evaluative adverbs (unexpectedly) or expressives (Determiner + stupid $+\mathrm{N}$, interjections, etc.). What happens for PP? There is clearly a tendency to project, see Chierchia \& McConnell-Ginet (1990); Geurts (1999); Beaver \& Geurts (2013) for different surveys. For instance, there is a strong intuition that all the forms in (5) presuppose that Paul has been smoking.

(5) a. Paul stopped smoking.

b. Paul didn't stop smoking.

c. Did Paul stop smoking?

d. It is possible that Paul stopped smoking.

e. If Paul stopped smoking, he must feel better.

Concerning the difference with conventional implicatures, conditional structures that suspend a PP seem to have no effect on implicatures, as suggested by the difference between (6a) and (6b), which sounds odd or heavily metalinguistic.

(6) a. If Paul has been smoking, he has stopped.

$\Varangle$ Paul has been smoking

b. ? If my friend is stupid, then my stupid friend found the solution.

However, this is not true for every type of conventional implicature, in particular for appositive relatives, see (7). In a context where Paul is John's friend, the speaker does not necessarily endorse the view that Paul is stupid. 
(7) If Paul is stupid, John can expect that his friend, who is not very clever, won't find the solution.

If projection for $\mathrm{PP}$ was uniform, the difference between conventional implicatures and PP would be essentially a matter of domain. For instance, conventional implicatures could perhaps be conceived as concerning all the domains where evaluation, whether emotional or intellectual, plays a central role. However it seems that, whereas implicatures project in a systematic way, it is not the case for PP. For instance, Karttunen (1971) introduced a difference between full factives like regret, whose PP always project, and semi-factives like discover, whose PP may be suspended, as in (8). See Beaver (2004) for a thorough discussion.

(8) a. If I discover that I was mistaken, I will admit publicly I was wrong. \& I was mistaken

b. If I regret that I was mistaken, I will admit publicly I was wrong. $\rightsquigarrow$ I was mistaken

Other ways to suspend the PP include the following ones.

1. Ignorance about the PP (Geurts, 1995), as in (9).

2. Negation of the PP in answers (Cummins et al. , 2013), as in (10), where the A1-B1 exchange is judged by speakers to be better than the A2-B2 exchange.

3. Abusch's $(2002 ; 2010)$ suspension test, as in (11)

(9) [Context: Paul has never seen or heard about Mary smoking, but she seems very nervous and restless. He wonders whether Mary has been smoking and is trying to stop]

Is Mary quitting smoking?

« Mary has been smoking

(10) A1 - Has John stopped smoking?

B1 - No, because he never smoked before.

A2 - Has John smoked again?

B2 - No, because he never smoked before.

(11) a. I have no idea whether Paul participated in the Road Race yesterday. But if he won it, then he has more victories than anyone else in history. (= Abusch's 2010 example 3d)

b. ?? I don't know if Paul participated in the race, but if Mary participated too, they probably ran together.

These and similar examples suggest that (i) PP projection has a certain degree of variability and (ii) that it is probably not just a matter of context or pragmatic considerations. Stalnaker (1974) defended the idea that projection is a default or preferred behavior, which can be be more or less plausible in different contexts. For instance, he explained the non-projection in (8a) by noting that, if the speaker of (8a) presupposes that she has missed the point, she necessarily realizes that she did so. So, by contraposition, if she does not realizes 
she has missed the point, she cannot presuppose that she did, hence the lack of commitment to the PP (absence of projection). So, a simple reasoning about the plausibility of the PP leads to abandoning it. Unfortunately, it is difficult to understand along the same lines the difference between too or again, which are robustly projective, and stop or win, for which the PP can be suspended more easily.

\section{$3 \quad$ Weak and strong triggers}

Examples (10) and (11) suggest that there at least two classes of triggers. Strong triggers (ST) always give rise to projection whereas weak triggers don't. This distinction is supported both by introspective and experimental data. Before presenting these data, however, I need to clarify what the ambition and limits of trigger taxonomies can be. This is done in the next section.

\subsection{A disclaimer in form of clarification}

In the previous section I have mentioned some well-known cases. A reviewer complains that I have confined my attention in this paper to "a rather limited number of presupposition triggers". This is quite true but can hardly be avoided. First, as evidenced by the (partial) list in Beaver \& Geurts (2013), there is a huge set of presumed PP triggers. The goal of the present paper is not to study the variability of triggers per se but only with respect to projection. There are a lot of important or minute differences that are not captured by a distinction in terms of projection and I did not intend to address them for a simple reason: I am unable to offer a 'complete' theory of PP triggers, meaning a theory in which each trigger would be described completely and correctly. I suspect that such a theory would require a detailed lexical analysis of each trigger. I am not aware of the existence of such a theory in the literature and I do not feel committed to proposing one.

Second, it is almost impossible to have clear-cut introspective intuitions on a very wide range of $\mathrm{PP}$ triggers, and it might be impossible to have clear intuitions on some triggers except in well-known (and generally trivial) cases. The strategy of the paper is, accordingly, to focus on a number of items that are considered as representative of some major categories: aspectual verbs like begin, emotive factives like regret, clefts, 'strong' adverbial triggers like too. Although their number is indeed limited, they span a not insignificant number of categories of PP triggers. I assume that the categories addressed in the paper are sufficiently interesting to be worth studying (I might be wrong).

My proposal is based to a large extent on experimental observations. The interest of an experimental approach is twofold. First, by going beyond the intuitions of isolated speakers, there is more chance to detect general tendencies, if any, and to compensate for the variability of introspective judgments. Second, an experimental perspective forces one to remain aware of the limits of 
large scale comparisons. Measuring the 'projectability' of triggers with comparison tests raises the question of the interpretation context. When we are given sentences in isolation or with a very limited or very specific context, we are not necessarily able to quickly scan a sufficiently large set of contexts in order to find a 'good' one, that is, a context that makes the sentence natural. So, a naturalness signal ${ }^{1}$ can reflect the degree of context accessibility/construction. To use a generic term, I will call the task of inferring a context that makes a linguistic stimulus plausible context abduction. To my best knowledge, there is at the moment no established technique for measuring context abduction. However, when a context can be provided which makes a linguistic stimulus natural, whereas the same stimulus is massively perceived as not natural in isolation, one can reasonably suppose that the licensing context cannot be easily abduced. This is the main idea behind the experiment reported in section 5.2. There, two triggers considered as strong are considered, regret and clefts. It is shown that, in suitable contexts, the PP of these triggers can be explicitly suspended without creating an impression of contradiction (it does not project). However, the contexts that make non-projection possible are not the same for the two triggers. Therefore, comparing the two triggers would be more risky because it would amount to comparing the behavior of two items in different contexts. Clearly, this is a general problem. Since PP triggers are very different, it is difficult and perhaps impossible to show in a rigorous way how exactly they compare to each other in terms of degree of projection. It is for instance possible that triggers that allow non-projection and are thereby similar differ nonetheless in terms of degree of projection strength but that the difference is impossible to evaluate. Once the context is given, this possible difference might disappear. When isolated sentences are considered, observed differences might be attributed to context abduction rather that resistance to projection. If the same contexts could be used, we would of course be in a better position to adopt a truly comparative perspective.

The upshot of these remarks is that, whereas it would be extremely interesting to compare triggers pairwise, it is also a difficult task, which seems to be beyond our reach for the time being.

\subsection{Introspective data}

The idea that PP triggers differ in their projection behavior is mentioned in several places in the linguistic and philosophical literature on PP. However, there is in general no systematic attempt to lay the foundations of a classification. Three notable exceptions are Abbott (2006), Abusch $(2002,2010)$ and Zeevat (1992). Zeevat's proposal is discussed in section 3.3. Its relation to the WT/ST distinction is less clear than in the works of Abbott and Abusch, which also offer the advantage of capitalizing on more recent contributions. In this section,

\footnotetext{
${ }^{1}$ Whether this signal is an explicit judgment or a different manifestation such as a reading time, fixation or ERP measure does not change the basic problem.
} 
I adopt Abbott's and Abusch's point of view and focus on the three main points that are to be found in their papers.

First, Horn (1972) identified a possibility of suspending a PP by means of a special if-clause or a may not construction (12a). According to him, the first sentence must be negative (12b)

(12) a. John does not realize that Sue loves him, if indeed she does.

b. \# If John realizes that Sue loves him (and in fact she may not), then he'll tell us.

One can observe that regret or again, for instance, are less felicitous in environments comparable to (12a).

(13) a. ? John does not regret that Sue loves him, if indeed she does.

b. ? John has not studied the problem again, if indeed he has studied it before.

Second, there is the discover/regret contrast mentioned by Karttunen, whose examples can be adapted to avoid the first-person effect mentioned by Stalnaker (see Beaver (2004)). Various similar observations suggest that epistemic factives like discover or know are $\mathrm{WT}$, whereas emotive factives like regret or be glad/sad/happy/surprised are ST.

(14) a. If someone discovers that I was mistaken, I will admit publicly I was wrong.

$\not \rightarrow$ the speaker was mistaken

b. If someone regrets that I was mistaken, I will admit publicly I was wrong.

$\rightsquigarrow$ the speaker was mistaken

Finally, there is Abusch's test, used in (11). The structure of the test sentences is: ? $p^{\prime}$, but if $p, q$, where $p$ presupposes $p^{\prime}$. What is tested is the possibility of accommodating the missing PP (whose truth has been suspended by a preliminary ignorance statement) in the local context corresponding to the antecedent of the if $p, q$ conditional.

Summarizing, there are reasons for distinguishing between WT and ST on a purely observational basis. However, the various observations that have been proposed give only a patchy picture of the weak/strong contrast. Table 1 gathers a number of introspective guesses about the category of different triggers and I provide illustrative examples in table $2 .^{2}$ The inventory of triggers follows Beaver \& Geurts (2013) with one exception. I did not consider manner adverbs such as quickly or clumsily, because they are part of the MC in most cases. In fact, if we were to accept that manner adverbs are PP triggers because they presuppose some event, I don't see why we should not include adjectives and other modifiers, on the account that they presuppose the existence of the entity to which they apply.

\footnotetext{
${ }^{2}$ I can't but repeat my cautionary statement of section 3.1: introspection can be misleading, especially, as here, when comparing very different items.
} 
The pseudo-Karttunen and Horn tests use negation and if as suspension operators. Horn's test is easier to use because it does not appeal to a conditional structure and I have focused on it for the two tables. I did not include examples for epistemic and emotive factives because they are discussed in the paper. For focus particles, I limited myself to mentioning exclusives. The presuppositional status of other focus particles has to be established. For instance, as explained in (Beaver \& Clark, 2008, pp. 70-72), scalar additives have a very different semantics than exclusives. In some cases, I realized that I had very shaky intuitions and added a "(?)" in table 1. I didn't use diacritics (?, \#, *) in table 2 , in order to let the reader develop her own intuition.

\begin{tabular}{|l|l|l|l|}
\hline Category & Items & Horn & Abusch \\
\hline Temporal markers & after, since & Weak (?) & Weak (?) \\
\hline Epistemic factive verbs & discover & Weak & Weak \\
\hline Emotive factive verbs & regret, be suprised & Strong & Strong \\
\hline Aspectual verbs & begin, stop & Weak & Weak \\
\hline Exclusives & only & Weak & Weak \\
\hline Scalar additives & even & Strong & Strong \\
\hline Discourse markers & too, again & Strong & Strong \\
\hline Sortal restrictors & bachelor & $(?)$ & $(?)$ \\
\hline Clefts & It's ... who & Weak & Weak \\
\hline Quantifiers & each, every & Weak & Weak (?) \\
\hline Definite descriptions & the, her & Weak & Weak \\
\hline Names & $\ldots$ & Weak & Weak \\
\hline
\end{tabular}

Table 1: Weak and strong triggers. A sample of items

\begin{tabular}{|ll|l|}
\hline Category & test type & Example \\
\hline Temporal markers & Horn & $\begin{array}{l}\text { Paul didn't change his mind since he read the re- } \\
\text { view, if indeed he read it. } \\
\text { I don't know whether Paul read the review, but, if } \\
\text { he changed his mind since, the final version of the } \\
\text { paper is going to be pretty different. }\end{array}$ \\
\hline Aspectual verbs & Horn & $\begin{array}{l}\text { Paul has not stopped smoking, if indeed he has } \\
\text { been smoking. } \\
\text { I don't know whether the victim has been smoking } \\
\text { before, but, if he has stopped smoking, we should } \\
\text { find traces of tobacco tar in his lungs. }\end{array}$ \\
\hline Exclusives & Horn & $\begin{array}{l}\text { I doubt that only Paul came, if indeed he came. } \\
\text { I don't know whether Paul came, but, if only him } \\
\text { came, it must have been disappointing. }\end{array}$ \\
\hline
\end{tabular}




\begin{tabular}{|c|c|c|}
\hline Scalar additives & Abusch & $\begin{array}{l}\text { I doubt that even Paul missed the target, if indeed } \\
\text { it would be THAT surprising. } \\
\text { I don't know whether Paul missing the target } \\
\text { would be very surprising, but, if even him missed } \\
\text { the target, we'll see what the others will do. }\end{array}$ \\
\hline Discourse markers & Abusch & $\begin{array}{l}\text { I doubt that Paul missed the target again, if in- } \\
\text { deed he missed it before. } \\
\text { I don't know whether Paul missed the target before, } \\
\text { but, if he missed it again, really, it's a pity. }\end{array}$ \\
\hline Sortal restrictors & Abusch & $\begin{array}{l}\text { This Jordan is not a bachelor, it seems, if indeed } \\
\text { Jordan is a male. } \\
\text { I don't know whether this super rich Jordan is a } \\
\text { male, but if he is a bachelor, he certainly has a lot } \\
\text { of women chasing after him. }\end{array}$ \\
\hline Clefts & Abusch & $\begin{array}{l}\text { It's not Paul who solved the problem, if indeed } \\
\text { someone solved it. } \\
\text { I don't know whether someone solved the problem, } \\
\text { but, if it's Paul, he must be very proud. }\end{array}$ \\
\hline Quantifiers & Abusch & $\begin{array}{l}\text { Since he settled only very recently, I doubt that } \\
\text { every professional nurse in the town met the new } \\
\text { doctor, if indeed there are professional nurses in } \\
\text { such a little town. } \\
\text { I don't know if any student cheated, but, if every } \\
\text { student who cheated has been expelled, we'll see if } \\
\text { some students are missing at the beginning of the } \\
\text { next term. }\end{array}$ \\
\hline Definite descriptions & Abusch & $\begin{array}{l}\text { Paul didn't find the key, if indeed there is a key } \\
\text { for this door. } \\
\text { I don't know if there is a key for this door, but, if } \\
\text { Paul found the key, we are lost. }\end{array}$ \\
\hline Names & Horn & $\begin{array}{l}\text { I never met this Mr Slush, if indeed there is some- } \\
\text { one with this name. } \\
\text { I don't know whether there is a Mr Slush, } \\
\text { but, if Dora met him she is in trouble. }\end{array}$ \\
\hline
\end{tabular}

Table 2: Weak and strong triggers. Examples of use

\subsection{Experimental data}

Certain-but not all-introspective observations are confirmed by the experiment reported in (Cummins et al. , 2013). Cummins et al. draw their initial motivation from Zeevat's (1992) distinction between three different types of triggers, a distinction which I summarize in the next paragraph.

Resolution triggers form the first category. They are strongly anaphoric, that is, they demand that the entities they refer to be present in the environment (discourse or situation) at the moment the PP trigger is used. Zeevat mentions def- 
inite descriptions, when- and after-clauses, as well as-tentatively-clefts. Lexical triggers correspond to "concepts with the applicability conditions", which means that certain conditions-corresponding to the $\mathrm{PP}-$ must be met for the concept to be applicable. An example provided by Zeevat is regret. At this stage, there is a significant complication. Zeevat assumes that a trigger can trigger several PP. For lexical triggers like verbs and nouns, the sortal information-whether we refer to an event or to an individual-is lexical in nature, whereas the descriptive information-what is predicated of the event or the individual-can be resolutive. For instance, Zeevat analyses an example like John believes that the king is bald as divided into a lexical presupposition, a resolution presupposition and a content (the MC of the present paper), see (15).

(15) John believes that the king is bald.

Lexical PP : $x$ ( $x$ has the type of individuals)

Resolution PP: $x \wedge k i n g(x)$

Content : $B_{j}$ bald $(x)$

Zeevat also considers triggers like again, also, another and too. They are characterized by their ability to involve parts of the context that are not normally accessible, as illustrated by (16).

(16) John believes that Mary was in Egypt. Sue was there too

Cummins et al. intend to compare the experimental correlates of lexical and resolution triggers. In fact, the set of triggers they choose contains (i) lexical triggers (regret, continue, stop), only, and comparatives, (ii) two triggers of the third type (again and too) and (iii) still. This is a little confusing but I assume that their goal is essentially to compare triggers which look for an antecedent (again, too and still) and triggers which express their PP directly in their lexical content. I will call the former anaphoric and the latter lexical. Concerning comparatives, I am skeptical as to their presuppositional status, since the alleged PP is not robust in a plain assertion: Mary is more clever than Paul, who is really rather stupid.

In their main experiment, Cummins et al. use an evaluation task where subjects have to rate some dialogs on a 5-point scale. The distribution of possibilities is as follows, for the trigger again. ${ }^{3}$

\footnotetext{
${ }^{3}$ As noted by a reviewer, the bottom right case is not very clear. The answer No, because he didn't lose his wallet before could be interpreted as Endorsing MC + Refuting PP. I won't try to take this interpretation into account, but its existence is an additional symptom of the difficulty of determining what the target of $\mathrm{Yes} / \mathrm{No}$ and although/because is exactly in this type of experiment.
} 


\begin{tabular}{|l|l|l|}
\hline \multicolumn{2}{|c|}{ Did Brian lose his wallet again? } \\
\hline Endorsing & Yes, he did lose his wallet again & $\begin{array}{l}\text { Yes, although he didn't lose his wal- } \\
\text { let before }\end{array}$ \\
\hline Refuting & $\begin{array}{l}\text { No, he didn't lose his wallet this } \\
\text { time }\end{array}$ & $\begin{array}{l}\text { No, because he didn't lose his wallet } \\
\text { before }\end{array}$ \\
\hline
\end{tabular}

Table 3: The four possibilities in Cummins et al. design

The initial expectations of the authors are that the combination of endorsing the $\mathrm{MC}$ and refuting the $\mathrm{PP}$ are better for anaphoric triggers than for lexical triggers and that the combination of refuting the $\mathrm{MC}$ and the $\mathrm{PP}$ is better for lexical triggers than for anaphoric triggers. The results are summarized in figure 1. The stars indicate significance in the difference between the scores for the No, because... (left bar) and Yes, although ... (right bar) answers.

Based on the introspective data of the previous section, one would expect that regret, continue, stop and only are WT, whereas still, ${ }^{4}$ again and too are ST. As indicated, I leave aside the case of comparatives. There is no significant difference for again and too, but they don't pattern alike. Still does not align with too and again, although it is considered to be a ST. Similarly, there is a difference for the (presumably) ST regret. So, the results delivered by the experiment do not coincide with introspection and call for an analysis of the task itself.

The main question that experiments of this type raise is to determine how the subjects interpret the dialogs they have to evaluate. Consider a set of pairs like those in table 3. When a subject sees the answer Yes, although he didn't lose his wallet before, what does she understand? It seems pretty obvious that the answerer means that she considers the proposition that Brian lost his wallet as true. But what is the meaning of although? It is unlikely that although signals an incompatibility between the fact of losing one's wallet and the proposition that one has not lost one's wallet before, because such a connection would be very obscure. It is likely, in contrast, that although is 'metalinguistic', that is, it indicates that the answerer has not used an appropriate expression. Is it also the case with because in other examples? What are the most reasonable predictions one can make, given the interpretations assigned to the different micro-dialogs presented in the experiment? Do these predictions correspond to what is observed by the authors? In the next section, I try to clarify the import of Cummins et al. experiment, before reconsidering the $\mathrm{WT} / \mathrm{ST}$ distinction in the light of introspective and experimental observations in sections 4 and 5 .

\footnotetext{
${ }^{4}$ In my intuition, still does not behave differently from too or again with respect to the Horn and Abusch tests.
} 


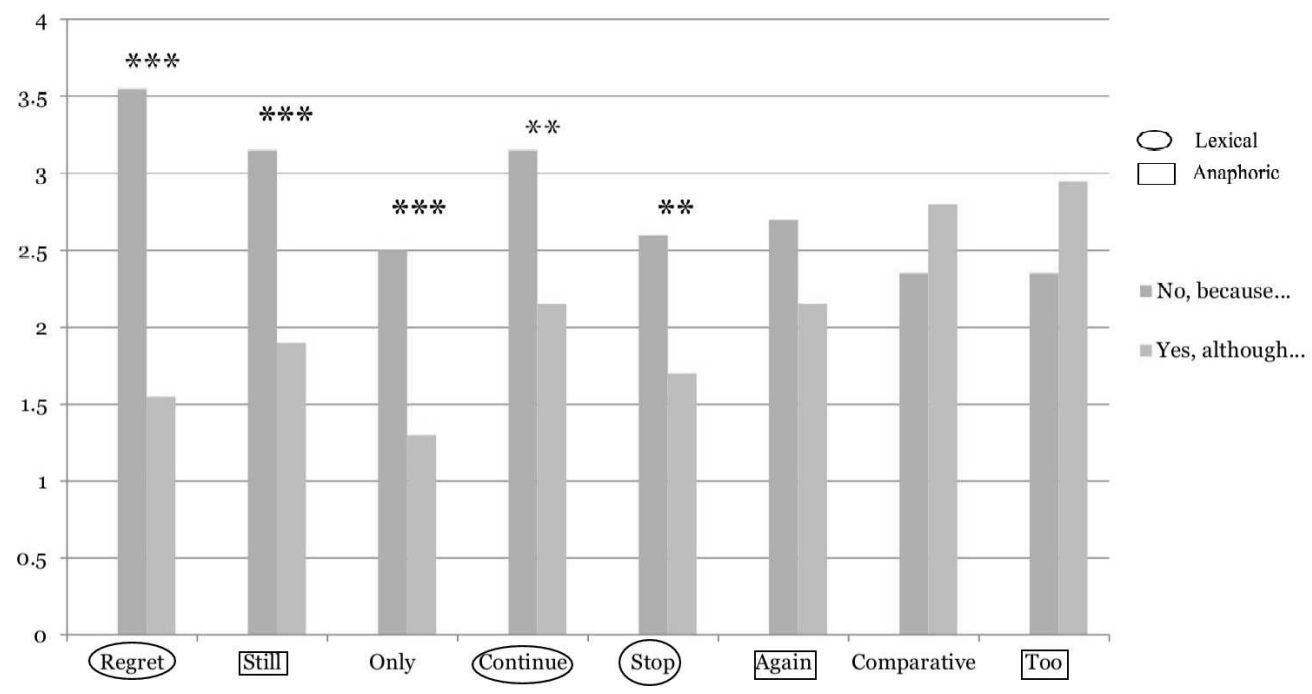

Fig. 1: Results of the second Cummins et al. experiment

\subsection{Discussion of the experiment}

Let us suppose that the yes and no particles in the various answers are free to target the $\mathrm{MC}$ alone, the $\mathrm{PP}$ alone or the $\mathrm{MC}+\mathrm{PP}$ combination. I will call this set of configurations the free attachment scenario. Under this scenario, there is no a priori plausibility in favor of one specific attachment, in comparison to the others. Clearly, this scenario is only a theoretical and rather implausible possibility. Nevertheless, it is useful to enumerate all the possibilities and sort out those that stand a chance.

Figure 2 shows the different possibilities of the free attachment scenario. Table 4 compares what is predicted under the free attachment scenario to what is observed by Cummins et al.

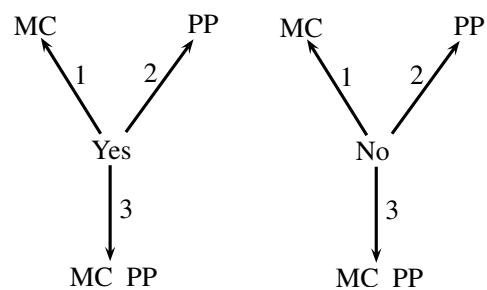

Fig. 2: The a priori possibilities for attachment 


\begin{tabular}{|c|c|c|c|}
\hline Category & Diagnostic & Prediction for ST and WT & Observed \\
\hline Yes-1 & depends on although & WT $=\mathrm{ST}$ & WT $\neq$ ST \\
\hline Yes-2 & contradictory (PP and not PP) & WT $=$ ST & WT $\neq$ ST \\
\hline Yes-3 & contradictory (PP and not PP) & WT $=$ ST & WT $\neq$ ST \\
\hline No-1 & explanation relation obscure & WT $=$ ST & WT $\neq$ ST \\
\hline No-2 & redundant explanation (X because X) & WT $=\mathrm{ST}$ & WT $\neq$ ST \\
\hline No-3 & ?OK & WT $=\mathrm{ST}$ & WT $\neq$ ST \\
\hline
\end{tabular}

Table 4: Predictions and observations

Let us first describe the predictions of table 4. With Yes-1, that is, when Yes targets the MC alone, we predict that the perceived quality of the Yes, although ... answer should depend on the interpretation of the although discourse marker. If it is interpreted as introducing only a correction, the answer should be judged as correct because its meaning can be paraphrased by "what you say MC is true, but your question presupposes something which is false". Although might also be interpreted as introducing an opposition. In that case, a form "A although $\mathrm{B}$ ' would mean ' $\mathrm{A}$ is true but $\mathrm{B}$, others things being equal, makes the probability of A decrease'. Under the opposition interpretation, the negation of the PP would be seen as making the probability of the MC decrease. It is not clear that this interpretation corresponds to our intuition in the general case. However, we might imagine contexts in which this dependency holds. For example, sailing across the Atlantic (as a pilot) probably demands some experience. So, one might think that, if you never crossed the Atlantic before and if you are not an experienced sailor, it is rather unlikely that you can succeed. If Paul is an unexperienced sailor, one might imagine a dialog like (17). In the case of (17), B's answer should sound natural, since it means something like "Yes, he has crossed the Atlantic, although it was his first experience".

$$
\begin{aligned}
& \text { A - Has Paul crossed the Atlantic again? } \\
& \text { B - Yes, although he never crossed it before. }
\end{aligned}
$$

Whatever the interpretation for although is, the prediction for an exclusive $\mathrm{MC}$ attachment is that ST and WT should not be different. Let us review more briefly the other attachment configurations. For Yes-2, the target of the answer is the PP, which makes the answer self-defeating, since the PP is endorsed and rejected at the same time. A similar diagnosis has to be made for Yes-3, where the MC and the PP are the targets. In the latter two cases, no difference between ST and WT is predicted. All in all, for Yes, the free attachment scenario does not predict any difference between WT and ST.

With No-1, the answer presents the negation of the PP as a reason to believe that the MC is false. The causal relation behind this reasoning is rather obscure in the general case. It might perhaps be clearer in particular contexts, like with although in the case of Yes-1. With No-2 (the PP is the target), because introduces a redundant explanation $(\neg p$ because $\neg p)$. The last case might be more felicitous. No targets the $\mathrm{MC}$ and the $\mathrm{PP}$ and the answer might be interpreted 
as 'it is not true that $\mathrm{A}_{\mathrm{MC}}$ and $\mathrm{B}_{\mathrm{PP}}$ because it is not true that $\mathrm{B}_{\mathrm{PP}}$ '. Under the three $N o$ versions, like in the case of Yes, the free attachment scenario does not predict any difference between WT and ST.

What are the observations? Generally speaking, the predictions of the abstract theory (free attachment) are not borne out. There are differences between triggers. How can we make sense of what Cummins et al. observe? The authors report two different findings. First the Yes, although ... answer is judged to be globally worse than the No, because... one. This can be explained straightforwardly if we assume that the answers target the conjunction of the MC and the PP. In that case, Yes, although ... is predicted to be anomalous for reasons we just saw with the comment of Yes-3 in table 4. The speaker endorses A and B and rejects B immediately after, which is a plain contradiction.

The second finding is the difference between WT and ST-or, more precisely, between certain items classified as ST and certain items classified as ST. Unfortunately, it turns out that the results of the experiment are difficult to interpret, given that there is a potential confound created by because. Under a descriptive (causal or logical) interpretation, 'A because B' presents B as a cause of or a reason for A. Under a metalinguistic interpretation, 'A because B', where A has a negative form $\neg C$, presents B as a reason for not using the form of words associated with $\mathrm{C}$.

Horn (2001, chap. 6) exposes all the intricacies of metalinguistic negation. The type of metalinguistic interpretation that is relevant in the context of the present paper can be described as in (18).

(18) A metalinguistic interpretation consists in assuming the existence of an eventuality while denying that it can be described correctly by a certain form of words.

To illustrate, consider (19). B1's answer is a plain negative answer. There was no event of Paul tidying up his room. This answer does not commit B1 to something happening at all. For all we know, Paul might have stayed quietly in his armchair. B2's answer, where the first syllable of tidy up is stressed, conveys the idea that something happened which cannot be properly called tidying up. It is well-known that marking focus with a stress, as here, is conducive to a contrast interpretation, in which several alternatives are competing (Rooth, 1992; Erteschik-Shir, 2007; Beaver \& Clark, 2008).

(19) A - Did Paul tidy up his room?

B1 - No, he didn't.

B2 - He didn't TIdy up his room.

In our case, the relation between the metalinguistic interpretation and the $\mathrm{PP}$ is relatively clear : the failure of the PP makes its trigger linguistically inappropriate. Note, however, that a metalinguistic interpretation can make use of the MC. For instance, in (20), B underlines the fact that the MC (Paul does not smoke) is not an exact description of the actual situation, although it bears some resemblance to it. 
A - Did Paul stop smoking?

B - He didn't STOP, but he is smoking less and less.

In order to interpret some of the results of the Cummins et al. experiment, one has to determine, as far as possible, whether the subjects see certain dialogs with a No, because ... answer as metalinguistic or descriptive. I won't consider the MC-addressing metalinguistic interpretations in discussing Cummins et al. experiment, because it is clear that the MC is not directly rejected in the $N o$, because ... answers. Consider dialog (21). A MC-addressing metalinguistic interpretation would amount to paraphrasing B's answer by 'It is not appropriate to say that Brian lost his wallet because he did not lose it before', which hardly makes sense.

$$
\begin{aligned}
& \text { A - Did Brian lose his wallet again? } \\
& \text { B - No, because he did not lose his wallet before. }
\end{aligned}
$$

However, the MC might be indirectly affected by the rejection of the PP, and I will have to take this possibility into account. It corresponds to what I have called the descriptive interpretation, in which negating the PP of the question ('Brian did not lose his wallet before') could make the probability of the negation of the MC ('Brian did not lose his wallet') increase.

How could we discriminate between the descriptive and the (PP-addressing) metalinguistic interpretation in our case? If the interpretation is descriptive, we have two possibilities. (i) The negation of the MC is caused or justified by the PP. This is very implausible in the general case. For instance, the No, because ... answer to a test sentence like Did Ben regret arguing with his boss? would be interpreted as "Ben has no negative feeling about arguing with his boss because he didn't argue with his boss". If this paraphrase means that Ben does not regret having argued with his boss because he didn't argue, what is explained or justified is not, in fact, the $\mathrm{MC}$ alone but the $\mathrm{MC}+\mathrm{PP}$ compound. If the paraphrase means that Ben has no negative feelings with the very idea of arguing with his boss because that did not happen, the meaning is at best unclear since the descriptive (causal/logical) link is not particularly obvious. More importantly, interpreting the No, because ... answer as a ' $\neg \mathrm{MC}$ because $\neg \mathrm{PP}$ ' pattern, is counterintuitive. If it was a natural answer, the following dialog should sound felicitous, which is not the case.

(22) A - Did Ben regret arguing with his boss?

B - Ben has no problem with the idea because he didn't argue with his boss.

(ii) The second possibility for the descriptive interpretation is that the $N o$, because ... answer rejects a logical and-conjunction because one of its terms is false. For instance, the following dialog (23) would receive the interpretation in (24). Similarly, the answer on the MC would correspond to (25).

(23) A - Does Toby continue to watch films?

B - No, because he didn't watch films before. 
(24) A - Does Toby watch films and did he watch films before?

B - No, because he didn't watch films before.

(25) A - Does Toby watch films and did he watch films before?

B - No, because he does not watch films.

Given (24) and (25), one would not expect much difference between a No, because answer refuting the PP (24) and a No, because ... answer refuting the MC (25). This is precisely what we don't observe. In a first experiment, Cummins et al. (2013) show very clearly that speakers prefer an attachment to the MC, which echoes previous similar experimental findings in (Jayez, 2010).

Summarizing, the most plausible candidate for the No, because ... answer is the PP-addressing metalinguistic interpretation, where a speaker underlines the inappropriateness of a linguistic form by denying the PP it triggers. Moreover, this interpretation is expected to remain rather marginal, because it creates a garden-path effect. The No, because part triggers an expectation that the answerer addresses the MC (descriptive interpretation) whereas the rest of the sequence only makes sense under a metalinguistic interpretation. Given that both Yes, although ... and $N o$, because ... answers are most naturally interpreted as metalinguistic, we can account for the observed difference between the scores for the Yes, although ... and the No, because ... answers. Moreover, we expect that, when the PP is difficult to suspend (ST), even the Yes, although ... answer will not be perceived as natural, so the difference between the Yes, although ... and the No, because ... will be smaller than when the PP is easier to suspend (WT).

We can conclude that Cummins et al. experiment confirms that there exists a difference in the robustness of the $\mathrm{PP}$, in agreement with the general feeling that some triggers (the ST) are more robust than others (the WT). However, the results leave us with two questions.

(1) The correspondence with the introspective data is imperfect. First, still and regret seem to be ST, whereas the experiment classifies them as WT. Second, the reason why again and too have inverse profiles is unclear, even if the difference between the scores fot the two answer types is not significant. Third, how is it that too has a markedly better score for the Yes, although ... answer than regret, only, continue or stop?

(2) The nature of the distinction between WT and ST remains a bit mysterious. Clearly, not all triggers behave the same. Is this sufficient to conclude that they fall into 'natural' classes, e.g. anaphoric vs. lexical or strong vs. weak. Should the difference be conceived instead on an item-per-item basis, or should we consider an intermediate taxonomy, with several small classes, possibly originating from a set of parameters? 


\section{Separation and M-relevance}

\subsection{Abbott on detachability}

Abbott (2006) offers a precious cue. She notes an apparent correlation between the status of triggers and the relation between MC and PP. The PP of ST correspond to pieces of information which are orthogonal to the MC, as evidenced by the nondetachability criterion, in the sense of Grice (1989, chap. 1-2). Grice discusses nondetachability in the context of conversational implicatures. A conversational implicature is non-detachable whenever it is not possible to 'say' the same thing, that is, to convey the same MC, without triggering the same conversational implicature, unless some feature of the alternative expression is relevant to the determination of the original implicature. Conversational implicatures are in general (but not always) nondetachable, whereas conventional implicatures are in general detachable. Interestingly, Grice (1989, p. 43) mentions the implicatures of PP triggers as nondetachable. In Paul stopped smoking, the proposition that Paul has been smoking will survive any attempt to reformulate "what is said' in Grice's sense.

Let us assume for the moment that Grice is right. Clearly, with ST, it is possible to 'say' the same thing without the PP. So, ST would be analogous to conventional implicatures, which, moreover, are reputedly hard to suspend (Potts, 2005), like ST. Abbott explains the common resistance of ST and conventional implicatures to suspension by resorting to a mechanism of intention attribution. A speaker has a choice between communicating the PP of a ST or not. Since the PP and the MC are informationally independent, and the speaker chose to communicate the PP, the latter must be part of her communicative intention. For instance, in using Mary hit the target again instead of Mary hit the target, a speaker lets us think that drawing our attention to the PP is an essential part of her message, hence the incompatibility with suspension, which would result into an incoherent conversational plan.

It seems that Abbott's account suffers from the same problem as Grice's. It is just technically incorrect to claim that PP of verbs like stop, or of WT in general, are nondetachable. There are perfectly good ways to 'say' the same thing without conveying the same PP. First, there is the possibility of asserting the MC alone, like Paul does not smoke with respect to Paul stopped smoking. One might object that, when using Paul does not smoke, we do not convey the same content because the transition from an activity of smoking to its negation gets lost. At the root of this objection, there is a frequent cognitive illusion about the MC. A plausible logical formula corresponding to Paul stopped smoking is shown in (26.2). $t$ is a time point (or a small incompressible time interval), $I_{1}$ and $I_{2}$ are time intervals, $\triangleleft(\triangleright)$ are the relations of right- (left)-abutting. $t \triangleleft I$ iff $t$ (or its smallest upper bound, if $t$ is an interval) is the greatest lower bound of $I$. $I \triangleright t$ is defined symmetrically. (26.2) says that there is a past time $t$ such that Paul has been smoking just before $t$ and didn't smoke for some time just after $t$. The MC is shown in (26.3). It says that John didn't smoke for some time, just after some time $t$. We might express the MC simply by saying Paul didn't 
smoke or Paul has not been smoking, or, if we are sure that Paul didn't start smoking again, by Paul does not smoke. Admittedly, we do not thereby convey the same information as with Paul stopped smoking, but the information we lose depends on the PP, not on the MC. We are just asserting that there is some past time point after which Paul didn't smoke, during some time interval which extends or not to the present, and this is indeed the 'substance' of the MC.

$$
\begin{aligned}
& \text { 1. } \quad \text { Paul stopped smoking } \\
& \text { 2. } \exists t, I_{1}, I_{2}\left(\text { past }(t) \& I_{1} \triangleright t \& \operatorname{smoke}\left(\text { Paul }, I_{1}\right) \& t \triangleleft I_{2} \& \neg \operatorname{smoke}\left(\text { Paul }, I_{2}\right)\right) \\
& \text { 3. } \exists t, \quad I_{2}\left(\text { past }(t) \& \quad t \triangleleft I_{2} \& \neg \operatorname{smoke}\left(\text { Paul, } I_{2}\right)\right)
\end{aligned}
$$

Interestingly, what I presented as a cognitive illusion is also to be found in theories of conventional implicatures. Potts (2005) sees implicatures as orthogonal to the rest of the sentence, in the sense that their truth of falsity does not affect the truth or falsity of the rest of the sentence. For example, in (1a), whether my friend finding the solution is unexpected or not or whether he is stupid or not does not affect the truth or falsity of my friend finding the solution. In contrast, with a sentence like Charles has talked to his sister, a PP failure-assume that Charles has in fact no sister-makes the whole event of speaking to Charles's sister impossible. In the present approach, the point is that the fact that Charles has no sister does not affect the main content that Charles has talked to someone, who happens, by virtue of the PP, to be his sister. The difference between a conventional implicature trigger and a PP weak trigger is that the MC and the implicature are clearly separated.

One might object that, in (26), the MC and the PP share the temporal variable $t$. If we assign different attitudes to presupposing and asserting, we can reformulate (26.2) as $\exists t$ (the speaker presupposes $\phi(t)$ \& the speaker asserts $\psi(t))$. A similar remark applies to factives, where the speaker presupposes a proposition and asserts that some agent entertains a certain attitude (knowing, discovering, regretting, etc.) with respect to the same proposition. The presence of a shared variable might appear to be the core of non-detachability. Unfortunately, a ST like again exhibits the same property. In saying Mary hit the target again, a speaker asserts that Mary hit the target at some time $t$ in the past and presupposes that Mary had hit the target at some point $t^{\prime}$ before $t$. So, the $t$ variable is shared. More generally, sharing a temporal variable is unavoidable in every situation where two events are declared and located with respect to each other.

Moreover, there is another formulation that does not convey the PP, the 'flat' one, in which the $\mathrm{MC}$ and the $\mathrm{PP}$ are juxtaposed within a conjunction, for instance, Paul has been smoking until Monday and didn't smoke (for some time) after Monday, instead of Paul stopped smoking on Monday. So, I don't see how to reconcile the MC vs. PP distinction with the idea that the PP is a nondetachable element. Of course, one could choose to reject the distinction and see WT as holistic bundles, but, under this view, it seems that nothing is left of the initial problem addressed by Abbott. If WT are not 'triggers', but rather co-entail the $\mathrm{MC}$ and the $\mathrm{PP}$, what is the whole discussion concerning the $\mathrm{WT} / \mathrm{ST}$ difference about? 
A reviewer mentions the characterization of soft triggers $(=\mathrm{WT})$ proposed by Abrusán (2011) and wonders what relation it might have to Abbott's idea. ${ }^{5}$ Abrusán considers only verbal WT and offers a predictive theory. Given a verbal WT, she proposes criteria to determine what the PP is. According to her definition 32 (p. 509), a PP is an entailment that obeys one of the two following conditions.

1. The entailment can be expressed by a sentence that is not necessarily about the event time of the matrix predicate, or,

2. the entailment can be expressed by a sentence that is not necessarily about the event time of the sentence that expresses the most direct answer to the background question determined by grammatical marking.

Condition 1 can be illustrated by Paul knows that Mary solved the problem. Clearly, the event of Mary solving the problem can span a different time interval than the interval corresponding to Paul's epistemic state. Condition 2 takes care of focus problems. For instance if the complement clause of a factive like discover is in focus, it is grammatically marked as answering a background question. The complement clause is then interpreted as expressing a secondary main point (in addition to the primary main point expressed by the matrix verb). Since a PP has to be temporally independent of the time span of every main point in the sentence, this predicts that, in some cases there is no room left for a PP. In example (27), where the embedded clause is in focus, there is no mention of an event that would be temporally disconnected from either the event expressed by the main verb or the event described by the embedded clause. So, nothing is presupposed, or, in the traditional terminology, the PP that Paul lied to the committee is suspended.

(27) If someone discovers that [Paul lied to the committee $]_{F}$ it will be a scandal

Two remarks are in order. First, Abrusán's approach predicts that the PP of discover-like verbs cannot be suspended unless the embedded clause is in focus. I wonder whether this is not too strong. Imagine the following dialog (28), in a context where Paul, an assistant of the President, has just testified before an official committee in a bribe case. The final conditional sentence does not commit the speaker to the belief that Paul lied. Must this sentence be in focus? It is not necessary that there be an intonational focus. One might argue that the clause is 'indirectly' in focus because it is an answer to a question that is relevant to the main question about Paul's situation. This certainly makes sense but could be taken to be just the joint effect of two aspects: (i) the context does not establish that Paul lied (otherwise, suspension would be impossible) and (ii), in general, answers to questions must not mention irrelevant information. If we apply Abrusán's analysis, S' = he has lied to the committee is not in focus, since there is not grammatical marking, and we get the following configuration: (i) there is a sentence S (someone discovers that S') with an entailment S', (ii) S' is not necessarily about the event time of the main verb (discover), (iii) there is no

\footnotetext{
${ }^{5}$ For time reasons, I was not able to properly analyze recent work by Romoli, which seems relevant to the issue addressed in this paper.
} 
background question determined by grammatical marking with respect to which S' could constitute an answer. So the PP projects, contrary to intuition in certain cases. We might drop the grammatical marking requirement but, in that case, we would have to say that every piece of information that might contribute to answer the main question will be 'in focus', or rather, in the terms of Simons et al. (2011), at-issue. According to Simons et al. (2011), only those elements of interpretation that are not at-issue can project, or, equivalently, at-issue elements cannot project. Their proposal would account for non-projection in (28), at least if one considers that the embedded clause he has lied to the committee is at-issue (= is relevant to a question under discussion). Another-conservative-option is to consider that the context makes one of the suspension/non-suspension interpretations more plausible than the other.

(28) A - What is exactly the situation of Paul?

B - I don't know for sure. At the moment, he seems to have the favors of the President, but, if someone discovers that he has lied to the committee, he is going to run into trouble.

The second remark to be made on Abrusán's approach is that, although she occasionally touches on the issue of ST, the goal of her paper is not to propose a theory of the distinction between WT and ST. This makes it hard to compare to Abbott's perspective and creates a more serious problem. She considers WT to be verbal, probably because she needs an event structure. It's not necessarily true (see tables 1 and 2) and makes it difficult to extract from her analysis of WT elements that could be directly recycled to address the WT/ST distinction.

\subsection{The separation intuition}

In spite of the nondetachability problem, there is an extremely useful insight in Abbott's approach, namely the idea that conventional implicatures and ST are somehow akin. Their relationship can be expressed very simply: for conventional implicatures as well as ST, the two components of the content, that is the nonMC and the MC, are separated in the message. The part of the message that conveys the MC does not convey the non-MC and reciprocally. As a result, with a ST, the PP-addressing metalinguistic interpretation, which depends on the rejection of the $\mathrm{PP}$, cannot concern the part of the message that conveys the $\mathrm{MC}$ since this part is appropriate. So, it must concern the trigger only. If one assumes with, among others, Partee (1991), that PP are unfocused by default-they normally constitute or contribute to the topic-they alone cannot be the target of a refutation unless some additional cue is provided, like a special stress, as in (29).

(29) Paul didn't hit the target aGAIN, since he missed it at his first try.

It follows from the separation property that ST are expected to be very poor targets under a PP-addressing metalinguistic interpretation, which is compatible with some of Cummins et al. observations. 
However, some other observations seem difficult to reconcile with the separation property. Although still, again and too would be classified as ST according to Abusch's suspension test (see example 31), they don't behave similarly according to the Cummins et al. test. In fact, a closer look reveals that too is the only item for which the Yes, although ... answer gets a better score than the No, because ... one. I conjecture that the main reason is that, in the setting of the experiment, the PP of too remains vague. The four stimuli used by Cummins et al. are of the type Did Ian win a prize too?, which would ideally require that we know who won a prize, apart from Ian. Although the standard theory has it that the PP would be someone else won a prize, it has been repeatedly noted that this PP is in most cases trivially satisfied and that the standard usage is that the actual PP involves a particular individual, different from Ian, winning a prize (see Kripke (2009)). I won't be concerned here with the exact presuppositional structure of too, which is the matter of some debate, but it is clear that a dialog like (30) is extremely difficult to interpret. In addition to the fact that the general preference for addressing the MC is defeated, a specific PP, of the form $x$ won a prize cannot be construed from the first sentence and the rejected PP in the No, because ... answer is a consequence of an (absent) specific PP and not a genuine PP. The configuration is not logically impossible, but requires probably some extra processing, which results in a stronger impression of incoherence, when compared to triggers like again or still.

$$
\begin{aligned}
& \text { A - Did Ian win a prize too? } \\
& \text { B - No, because no one else won a prize. }
\end{aligned}
$$

Summarizing, the separation property provides a convenient explanation for the metalinguistic interpretations and, since I have argued that the most plausible interpretation is metalinguistic in the case of the Cummins et al. experiment., this property is a good candidate for explaining their observations.

However, I have not discussed Abusch's suspension test, exemplified in table 2 and in (31) below. Abusch's idea is that ST do not permit PP (local) accommodation, in particular in the antecedent of a conditional, as in (31). One can observe that, more generally, ST like still, again or too cannot be easily suspended. In contrast to (9), repeated below, (32) and (33) are infelicitous.

(31) a. ?? I don't know if Paul participated in the race, but if Mary participated too, they probably ran together.

b. ?? I don't know if Paul participated in the race before, but if he participated again, he must be very proud.

c. ?? I don't know if Paul was in the garden, but if he is still there, ask him to bring back the spade.

(9) [Context: Paul has never seen Mary smoking, but she seems very nervous and restless]

Is Mary quitting smoking?

$\Varangle \rightarrow$ Mary has been smoking 
(32) [Context: Paul has never seen or heard about Mary smoking, but she seems very nervous and restless]

a. Is Mary still smoking?

b. Is Mary smoking again?

(33) [Context: Paul has no evidence that Mary has a particular problem, for instance personal difficulties]

Does Mary have professional problems too?

Examples of this kind do not seem to have much to do with a metalinguistic interpretation. They are not isolated cases. Consider sentences of the type illustrated in (34). Although (34a) and (34b) refer to the same set of situations, the latter is less natural.

(34) a. I saw that Paul smokes, but I don't know whether he is starting or just continuing.

b. ? I saw that Paul smokes, but I don't know whether he is starting or still smoking.

The contrast between prefixes and adverbs expressing repetition provides similar observations. In many Romance languages the $r e-$ prefix is used to express repetition (Sletsjøe, 1979). For example, in French, there are two alternative forms for expressing repetition. One can use a ST like encore, à/de nouveau (again), une fois de plus (once more), or, in some cases, prefix a verb with the iterative marker re-. Imagine that Paul climbed the Matterhorn (Cervin in French) twice. One can express the repetition as in (35d) or (35e), where the repetition prefix is underlined.

(35) a. Paul climbed the Matterhorn

b. Paul a fait le Cervin

c. Paul climbed the Matterhorn again

d. Paul a encore fait le Cervin

e. Paul a refait le Cervin

Now, suppose that Paul is climbing the Matterhorn with Mary and that she is impressed by the easiness with which he orients himself, finding his way through the different possible paths and avoiding dangerous areas. She tells herself (36). The intended interpretation is that Mary suspects that Paul climbed the Matterhorn before and that he didn't let her know, maybe for showing off. Under this interpretation, (36b) is not felicitous, like its English counterpart (36c). In contrast, (36a) is much better.

(36) a. C'est étonnant! Peut-être qu'il le refait et qu'il n'a pas voulu me le dire.

b. ?? C'est étonnant! Peut-être qu'il le fait encore et qu'il n'a pas voulu me le dire.

c. ?? Amazing! Maybe he climbs it again and he didn't wish to tell me. 
Mary observes the efficiency of Paul (the 'data') and she makes an hypothesis in order to explain it. In other terms, she selects a dependency corresponding to an acceptable likelihood. In Bayesian terms, the appropriate expression is a conditional probability, the probability of observing the (efficient) behavior of Paul assuming both the MC (he is climbing the Matterhorn) and the PP (he has done that before), in symbols $(\operatorname{Pr}($ efficiency $\mid \mathrm{MC} \& \mathrm{PP}))$. Note that the MC is involved and cannot be taken out of the probabilistic dependency. Suppose that we are in a context where Paul is not climbing the Matterhorn, Mary could not observe that he is particularly efficient. The difference between (36a) and (36b) is due to the lexical packaging of an information piece which is otherwise perfectly identical in the two cases.

Examples (32), (33), (34), (35) and (36) suggest that a PP associated with a $\mathrm{ST}$ cannot be in focus. The infelicitous questions or suppositions in the various examples try to address the PP of triggers like again or still, that is, triggers that express the PP separately from the MC. With other triggers, the MC and the $\mathrm{PP}$ are integrated. The PP is related to an argument of the MC verb. A notable exception is only, which conveys a part of the MC as well as a part of the PP. For instance, as a an NP-modifier, only acts on a NP and a VP, assembling the content of both to produce the PP and the MC. So, there is no separation between the two parts of the content, but, rather, an entanglement determined by only. ${ }^{6}$

\begin{tabular}{|l|l|}
\hline Type of trigger & Mode of integration \\
\hline Temporal markers & $\mathrm{PP}=$ complement \\
\hline Factives & $\mathrm{PP}=$ complement \\
\hline Aspectual verbs & $\mathrm{PP}$ conveyed by complement \\
\hline Exclusives & convey a part of the MC \\
\hline Sortal restrictors & $\mathrm{PP}$ conveyed by a complement of the MC verb \\
\hline Clefts & PP expressed by the complement \\
\hline Quantifiers & PP expressed by an argument of the main verb \\
\hline Determiners & PP expressed by an argument of the main verb \\
\hline Proper nouns & PP expressed by an argument of the main verb \\
\hline
\end{tabular}

Table 5: MC/PP Integration

\footnotetext{
${ }^{6}$ When it modifies a subject NP, only can be described categorially as in (a), where $s, s^{\prime}$ and $s^{\prime \prime}$ are string variables, a form $s: x, y$ denotes the fact that string $s$ has the semantic type $x$ and the syntactic type $y, u$ is the semantic type of individuals, $\mathcal{P}$ the semantic type of properties and $t$ the semantic type of truth-values.
}

(a) 1. syntax: $\left(s^{\prime \prime}: t, \mathrm{~S} / s^{\prime}: \mathcal{P}, \mathrm{VP}\right) / s: u, \mathrm{NP}$

2. $\mathrm{PP}=\mathcal{P}(u), \mathrm{MC}=\forall x((x \neq u) \Rightarrow \neg \mathcal{P}(x)$ 
The resistance of ST to focusing does not explain Abusch's observations. In (11b), repeated below, the PP triggered by too is not in focus alone, unlike in the previous examples. However, there is a common feature between the two cases, the fact that an operator (question, if) cannot access a part of the message that is not involved in the expression of the MC. E.g., in (34a), (36b,c) and (11b), the operators have to access the ST trigger, to apply a focus or conditional operator. With (11b), the desired interpretation is 'If Paul participated (PP) and if Mary participated too', that is, a local accommodation configuration in which the PP is in the scope of the conditional operator. As noted by Abusch, such a configuration is problematic. It seems, in fact, that the operator can't but ignore the PP triggered by a ST, exactly like the focus operator has to ignore the PP of ST. In the next section, I try to account for this particular behavior of operators with ST.

(11) a. I have no idea whether Paul participated in the Road Race yesterday. But if he won it, then he has more victories than anyone else in history. (= Abusch's 2010 example 3d)

b. ?? I don't know if Paul participated in the race, but if Mary participated too, they probably ran together.

\subsection{Integrating M-relevance}

In this section, I show that, in order to exploit the separation property, we need another ingredient (called $M$-relevance, for monologal relevance) which allows us to understand why separation has the effect it has. Unless otherwise indicated, I consider only non-metalinguistic interpretations.

Introducing M-relevance Jayez (2010), elaborating on an earlier proposal by Ducrot (1972) shows experimentally that it is practically impossible to construct a discourse attachment to the non-MC exclusively, at least for a subset of discourse relations that involve Bayesian relevance, à la Merin (1999, 2003), see definition (37). ${ }^{7}$ In this paper, relevance is restricted to monologues, and I will use the label M-relevance to make this restriction more apparent.

(37) A proposition $p$ is positively (negatively) relevant to another proposition $q$ in a belief state $\mathcal{B}={ }_{\mathrm{df}} \log \left[\operatorname{Pr}_{\mathcal{B}}(p \mid q) / \operatorname{Pr}_{\mathcal{B}}(p \mid \neg q)\right]$ is $>0(<0)$. So, relevance is just the difference between the log-likelihoods. Intuitively, $p$ is positively (negatively) relevant to $q$ iff updating the current context (belief state) $\mathcal{B}$ with $q$ makes the probability of $p$ increase (decrease).

Causal relations are a case in point. With 'A because B' patterns, $\mathrm{A}$ is presented as having positive M-relevance to B or, equivalently, B is presented as

\footnotetext{
${ }^{7}$ I follow Merin and the standard practice of using log of quotients instead of quotients. This ensures that relevance is null whenever $\operatorname{Pr}(p \mid q)=\operatorname{Pr}(p \mid \neg q)$. I am not convinced that the present notion of relevance is necessarily the best but I don't know of any proposal about how to compare different notions.
} 
making the probability of A increase. (38.a) exemplifies an attachment to the MC: it is because smoking is unhealthy that Paul does not smoke. Whatever (38.b) means, it cannot mean that Paul smoked because he liked that, ${ }^{8}$ that is, any attachment to the PP alone is precluded. Jayez (2010) shows that this restriction holds for conventional implicatures as well. With abductive relations, where the speaker deduces possible causes from observations, the MC can correspond to the hypothetical cause. For (38a) and (9), we have the M-relevance relations in table 6 .

(38) a. Paul stopped smoking because it's unhealthy.

b. Paul stopped smoking because he liked it.

(9) [Context: Paul has never seen or heard about Mary smoking, but she seems very nervous and restless. He wonders whether Mary has been smoking and is trying to stop]

Is Mary quitting smoking?

$\Varangle \rightarrow$ Mary has been smoking

\begin{tabular}{l|l}
\hline Paul stopped smoking & because it's unhealthy \\
$\log [\operatorname{Pr}($ bad-for-health $\mid \neg$ smoke $) / \operatorname{Pr}($ bad-for-health $\mid$ smoke $)]$ \\
\hline Mary might be quitting smoking $\mid$ because she is nervous \\
$\log [\operatorname{Pr}($ nervous $\mid$ quit-smoking $) / \operatorname{Pr}($ nervous $\mid \neg$ quit-smoking $)]$ \\
\hline
\end{tabular}

Table 6: M-Relevance relations

The obligatory character of an attachment to the MC for M-relevant constituents is expressed in (39). The interaction between M-relevance and attachment corresponds to the following intuition. When a speaker makes it manifest that she introduces in the discourse some information that potentially makes the probability of a certain proposition increase or decrease, this information must concern the part of the message that conveys the $\mathrm{MC}$, although, as we will see below, it can also concern other parts. It is not surprising that the MC should be involved, given that the $\mathrm{MC}$ corresponds to the foregrounded information in linguistic communication. ${ }^{9}$ It would be much more surprising that a speaker bothers to mark a certain content as foregrounded (the MC) and forgets it altogether in the rest of the discourse (see Jayez (2014) for a detailed discussion). This makes sense for monologues. For dialogs the situation is more complex, because an addressee can reject implicitly or explicitly the foreground/background

${ }^{8}$ A reviewer notes that (38.b) might mean that the reason for Paul stopping smoking is that he liked smoking. This is true, but, in that case, the attachment is to the MC and the plausible interpretations are hard to get (maybe Paul is wary of addiction?).

9 This is a widely shared intuition, see for instance (Grice, 1989, pp. 121-122) and (Abrusán, 2011). 
divide of the speaker. I won't discuss the case of dialogs in this paper and will focus only on M-relevance.

The notion of M-relevance extends to suspension operators (negation, interrogation, if). When a speaker applies such an operator to a proposition, the MC must be involved for the same reason as with M-relevance attachments: why would the speaker foreground some information if it was to be ignored? ${ }^{10}$

\section{(39) M-relevance and MC}

A M-relevance-based attachment must exploit the MC.

(39) leaves open the possibility that the MC acts as a cause or a consequence, in patterns of the form $\mathrm{MC} \stackrel{\text { cause }}{\longrightarrow} X, X \stackrel{\text { cause }}{\longrightarrow} \mathrm{MC}$, or $\mathrm{MC} \stackrel{\text { cause }}{\longrightarrow} \neg X$ and $X \stackrel{\text { cause }}{\longrightarrow} \neg \mathrm{MC}$ in the case of opposition relations. Importantly, (39) must not be interpreted as implying that the probability of the MC is modified. For instance, in a sentence like Paul lost the race although he had had a hard training period, the probability of Paul losing the race is maximal for the speaker. Relevance concerns potential probability modifications. $p$ is potentially relevant to $q$ in $\mathcal{B}$ if, in any context (belief state) $\mathcal{B}^{\prime}$ minimally different from $\mathcal{B}$ and such that $\mathcal{B}^{\prime}$ does not satisfy $p$ and does not satisfy $q$, updating $\mathcal{B}^{\prime}$ with $q$ makes the probability of $p$ increase or decrease. Constructing a proper definition of 'minimally different from' is a complex problem and I assume that most definitions proposed in the literature are compatible with the definition of potential relevance (see van Benthem et al. (2009) for a recent discussion of the problem from the point of view of modal logic).

Attachments to both the MC and the non-MC are not disallowed by Mrelevance. For instance, in Paul has a strong will since he stopped smoking, attributing a strong will to Paul is motivated by the conjunction of the fact that he was a smoker up to some point in the past and that he has not been smoking after that point. ${ }^{11}$ This is exactly the type of attachment we have in (9). The possibility that Mary has been smoking and is no longer smoking is motivated by the observation that she is somewhat agitated. There are similar observations for ST, e.g. Paul has hit the target. If he hits it again, it will be a real feat. If the PP pf a ST can be taken into account in an attachment, what does the distinction between WT and ST consist of exactly?

Connecting M-relevance and separation In section 4.2, we have seen that focus- and if-operators cannot access the PP unless it is conveyed by a part of the linguistic message that also conveys elements of the MC. M-relevance demands that a relevance-based discourse relation in a monologue make use of the MC. Is there a relation between the two constraints?

An operator must apply to (access) a part of the linguistic message. This part is not necessarily the whole sequence of words on the right of the opera-

$\overline{10}$ A reminder: I am not talking about the metalinguistic interpretation in the present section

${ }^{11}$ A reviewer proposes Paul has a strong will since he isn't smoking as an example where only the $\mathrm{MC}$ is present. 
tor, as evidenced by focus-, question- and if-operators, which shunt ST triggers. A discourse relation is much more 'abstract' or 'non-local'. It can exploit the propositional information in general, no matter what its linguistic realization or its degree of implicitness are. Thus, it is not surprising that discourse relations can access the PP of ST, since they are part of the general discourse information. This difference granted, the MC is an obligatory ingredient for operators and discourse relations and this common constraint interacts with the nature of operators and discourse relations to produce two different but related effects. With relevance discourse relations, the MC is necessarily used, but other pieces of information, including the PP can contribute to support the relation. With operators, again, the MC is a necessary ingredient, but, in contrast with discourse relations, the operator cannot exploit several additional sources, because it cannot abandon its argument to jump to another part of the sentence, which entails that it can apply only to a PP if this PP is conveyed by the same part as the MC.

I register the constraint of obligatory attachment to a MC-part in (38).

\section{(40) M-relevance and separation}

A (non-metalinguistic) M-relevance-based discourse attachment in a monologue cannot target a part of the message that does not convey elements of the MC.

A consequence of (40) is that, for ST, the PP will tend to be ignored, except under the metalinguistic interpretation with a special focus marking on the PP, typically, some focal stress as in (29). This accounts for the observation that, in general, the PP of ST cannot be suspended. However, one may wonder what happens if the context somehow makes the PP salient. In section 5.1, I report experimental findings which show that suspending the PP of too (a ST) is possible when the process of local accommodation is 'boosted' by the interpretation process. For WT, (40) predicts that a relevance-based attachment will use the $\mathrm{MC}$ and can also use the PP if we have a form of words that assembles the $\mathrm{PP}$ of a ST with its MC, instead of putting them into two different slots of the message. However, emotive factives are classified as ST, which does not square well with my analysis. In section 5.2, I show that the apparent counterexample of factives can be dealt with in terms of context abduction and is not, in fact, an exception to constraint (40).

\section{$5 \quad$ Loose ends}

\subsection{Accommodation}

If we think of the way in which we learn to use presuppositional terms, it is highly likely that in most contexts, the PP is satisfied. For instance, it is repeatedly

noted in the literature on first language acquisition that again or more are part of the young ( $\leq 2$ years) child lexicon, see Kauschke \& Hofmeister (2002) for wieder 
(again). For English, the consultation of http://childfreq.sumsar.net/ suggests that more and again are more frequent than stop and start. ${ }^{12}$ This does not necessarily indicate that ST are learned before WT because they are strong. They could simply correspond to situations that a young child is likely to encounter and/or to categorize. It is nonetheless interesting that all those triggers are learned at a very early stage in language development, since they involve very robust $\mathrm{PP}$, or in a more linguistic terminology, quasi-automatic projection. This is in agreement with our intuition that PP triggers would lose any presuppositional character if they were learned in just random contexts, including those in which the PP is not satisfied. ${ }^{13}$ The fact that presuppositional terms are learned preferably or exclusively in contexts where there is no PP failure lends support to Lassiter's analysis in terms of probability threshold (Lassiter, 2012). According to Lassiter, whenever $p$ is an atomic sentence which carries the semantic PP $\underline{p}$, "a speaker should not utter $p$ unless $\operatorname{Pr}(\underline{p})$ meets or exceeds a high threshold $\bar{\theta}$ according to her epistemic state, and she believes that her audience also assigns $p$ at least probability $\theta . "$ (Lassiter, 2012, def. 9). This constraint might be too strong and reproduce, in a probabilistic setting, the difficulties which affect the notion of common ground. Accordingly, I will use only the first part of the constraint, that is, I will assume that a speaker communicates that the PP is highly probable in her own epistemic state.

When a PP has not been explicitly endorsed by the speaker or is not easily recoverable from the context, there is always the possibility of accommodating the PP, that is, of assuming, at least provisionally, that it is true. The notion of accommodation has a long history within the research field of PP and I won't try to comment on the different approaches. Suffice it to say that it is to be expected that ST are resistant to accommodation, as noted by Abusch (2002, 2010). Accommodation is used when the PP is associated with the MC, since the entry point of a relevance-based interpretation is the MC carrier. With ST, the interpretation does not take the PP into account (it does not have to). As a result, if the PP does not have a strong probability at start, it will not be accommodated, which may result in a conflict. Let $S$ be a sentence containing a trigger $T$ and $C$ a context for this sentence. The appropriateness ${ }^{14}$ of a $\mathrm{WT}$ in the sentence, given the context, is jointly controlled by the $\mathrm{MC}$ of the sentence in the context and the PP of the trigger in the contextualized sentence. This is very easy to formulate in Bayesian terms, by means of the conditional probability

${ }^{12}$ Interestingly, as observed by a reviewer, one might argue that stop is more similar to more and again than start.

${ }^{13}$ As noted by a reviewer, it is possible-and probable in fact-that children dot not master the whole spectrum of usages of a given trigger. However, it is difficult to imagine that they would use presuppositional terms like again or more with a PP failure.

14 The notion of appropriateness is to be kept distinct from that of truth. Obviously, a trigger can be used felicitously with respect to the belief state of the speaker and be inadequate with respect to the actual state of affairs. 
that the appropriateness of the trigger reaches a certain value, say $x$, given that the probabilities for the MC and the PP reach certain values, say $y$ and $z{ }^{15}$

$$
\operatorname{Pr}(\text { appropriate }(T, S, C)=x \mid \operatorname{Pr}(M C(S, C))=y \& \operatorname{Pr}(P P(T, S, C)=z))
$$

Equivalently, in a traditional causal network representation Pearl (2009), the appropriateness of a WT is represented as a collider assembling the $\mathrm{MC}$ and the $\mathrm{PP}$, whereas a ST is appropriate only in virtue of the PP it expresses (figure 3). Colliders are graphs where a dependent variable is influenced by several factors simultaneously, which amounts to having a terminal node (the dependent variable) connected to the various factors by a bunch of edges.

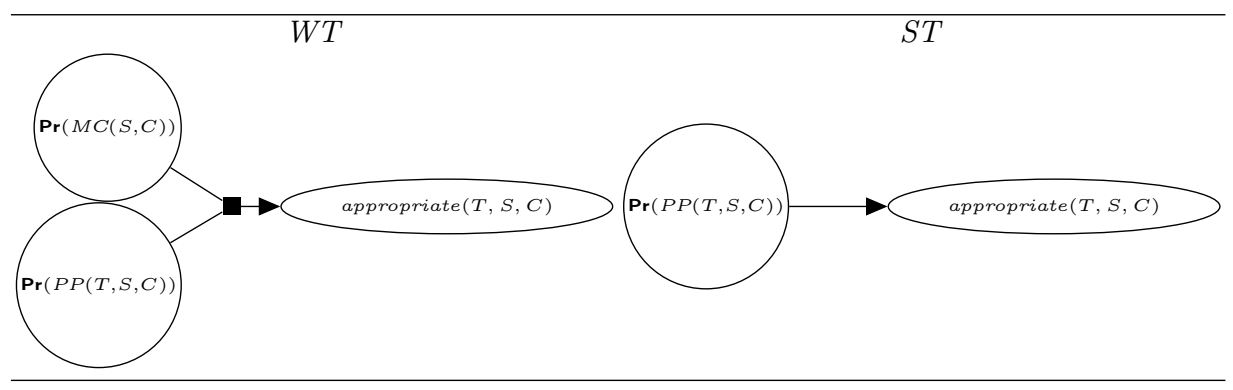

Fig. 3: Influence for a WT and a ST

By backward reasoning, when the appropriateness and the MC probability of a WT are determined, the probability of the PP can be adjusted, and possibly raised to a sufficient level if it is not determined (accommodation). Nothing similar can happen for ST since the probability adjustments are relativized to those parts of the network that contain PP nodes. However, it is possible that independent material makes the PP of a ST highly probable. In that case, ST are rescued. For instance Jayez \& Mongelli (2013) and Jayez et al. (2013) show that the French counterparts of stimuli similar to (42) are positively evaluated. More interestingly, there is no significant difference between (42a) and (42b) patterns, which suggests that the hypothetical missing PP (Paul goes to the party) is accommodated independently of the presence of too. This is most probably due the discourse structure, which favors a sort of counterfactual reasoning attributed to Paul. When but is substituted for because, the subjects rate the resulting sentences as very poor. The contrast but/because is illustrated in figure 4. So, the missing PP is not really 'accommodated', in the sense of activated to satisfy the requirements of a trigger, but rather independently activated and retrieved by the trigger.

${ }^{15}$ In contrast to what is usually done in Bayesian networks, the factors that influence the dependent variable (the appropriateness) are not sets of values of a random variable, but sets of values of a probability. 
(42) Context: Paul has been invited to a party. He is on very bad terms with Mary and they would prefer not to come across each other. Paul thinks that Mary might have been invited as well.

a. I don't know whether Paul will go to the party because/??but, if Mary goes, it will be embarrassing.

b. I don't know whether Paul will go to the party because/??but, if Mary goes too, it will be embarrassing.

Score distribution by discourse marker



Fig. 4: Accommodation-like effect with because and but

\subsection{Are factives a problem?}

Abbott (2006) notes that the existence of verbs like regret is a problem for her idea that the difference between WT and ST stems from nondetachability. Regret is classified as a ST by Abusch, whom Abbott follows, but is nonetheless detachable. I won't try to assess the nondetachability of regret since the concept is slippery. Rather, I turn to recent experimental results in Jayez et al. (2013), which suggest that regret is not a ST, even when one sticks to the framework of Abusch. Jayez et al. use French stimuli on the model of (43), which is the English translation of one of the control-target pairs. In the control condition, the speaker considers the PP as probable whereas she is agnostic about it in the target condition. Subjects must rate the sentences on a 7 point scale $(1=$ extremely obscure, $7=$ totally natural). The goal of the experiment is to detect a significant different between the control and the target conditions. If regret is a $\mathrm{ST}$, one expects the scores for the target condition to be significantly worse than 
those for the control condition. A similar experiment was designed for clefts on the model of (44).

(43) Context: Véronique is wondering whether she will change her current car for a bigger one.

a. I think that Véronique bought a bigger model. If she regrets it later, it will be difficult to change again. [control]

b. I wonder whether Véronique bought a bigger model, but, if she regrets it later, it will be difficult to change again. [target]

(44) Context: An employee cannot log in on his computer.

a. I think that someone changed the password. If it was my colleague, I just have to wait to ask him. [control]

b. I don't know whether someone changed the password but, if it was my colleague, I just have to wait to ask him. [target]

Figure (5) shows the (smoothed) density plots of the scores in the control and target conditions for regret and clefts. The curves for the two conditions are extremely similar. The statistical analysis reported in (Jayez et al., 2013, sec. 1.3.2) failed to detect any difference between the two conditions for regret and for clefts. Note that clefts are considered by Abusch to be ST. Therefore, the observations are doubly problematic.
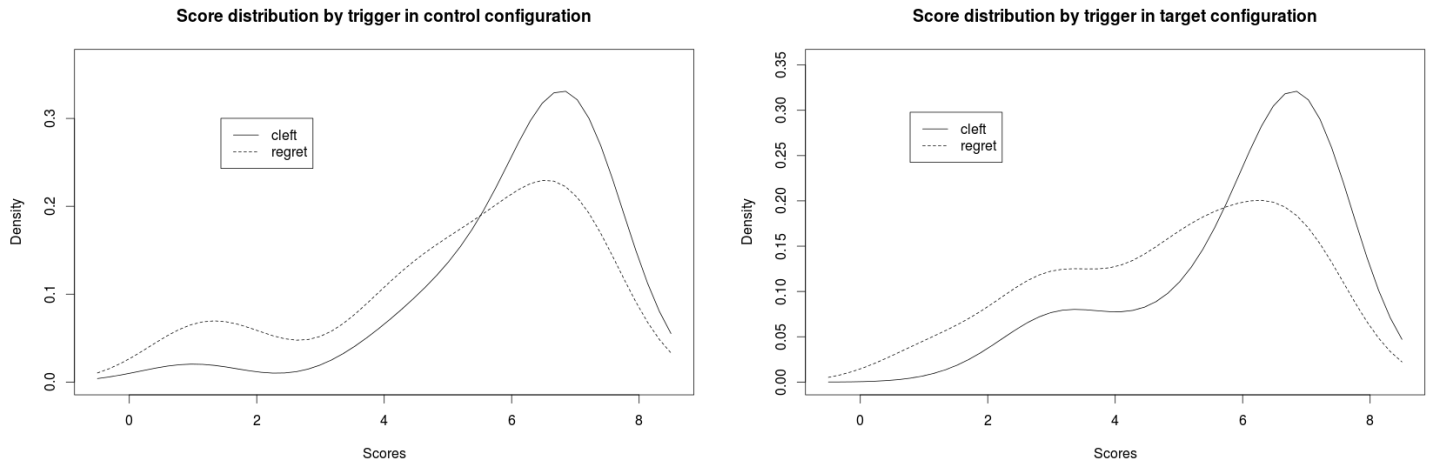

Fig. 5: Density plot by trigger under control and target conditions

These results suggest that regret is not intrinsically a ST. Rather, the information it conveys makes it relatively difficult to find a context in which the PP it triggers is suspended. But that does not mean that it is impossible. In other words, with regret and other similar triggers, the problem is that of con- 
text abduction, the possibility of constructing contexts in which an expression is felicitous. Context abduction depends on the lexical content of the expression and probably the existence of alternatives, as suggested by Abbott. Abbott considers that regret and similar emotive factives are nondetachable. Yet, like in the case of stop, there are relatively natural paraphrases of the attitude expressed by regret that lack factivity. To regret that $p$ is to prefer a counterfactual situation in which $p$ did not take place. To prefer a situation in which $p$ is false, irrespective of the truth-conditional status of $p$, amounts to entertaining the same attitude as that expressed by regret, minus the factivity. (45b) does not commit the speaker to a belief that Paul got a Porsche. It is indeed difficult to build very quickly a context in which one would use (45a) instead of (45b) without having the intention to communicate that the $\mathrm{PP}$ is true.

(45) a. Paul regrets to have bought a Porsche

b. Paul does not like the idea of having a Porsche

Concerning semi-factives like discover, Simons (2007) argues that verbs like discover or realize imply accessing some evidence that the PP is true. It follows that semi-factives are similar to examples like (46). In such cases, we observe exactly the same behavior as with discover and its mates, namely: (i) in positive assertions (46a), the conveyed information entails that Paul missed the point and it is not possible to cancel the latter proposition (46b), and (ii), in suspension environments, there is no longer an entailment (46c). With a negation, we have a choice between two interpretations: either we deny the existence of a proof, which amounts to suspending the $\mathrm{PP}$ in the case of discover, or we deny that Paul is aware of the truth, which amounts to preserving the PP.

(46) a. Paul has a proof/conclusive evidence that he missed the point.

b. Paul has a proof/conclusive evidence that he missed the point but ??he didn't miss it.

c. If Paul has a proof/conclusive evidence that he missed the point, ...

Generalizing, when the MC entails the PP or makes it highly probable, the very mention of the trigger is sufficient to activate the PP. This accounts for the win vs. too contrast re-illustrated in (47). Winning implies normally participating, so the $\mathrm{PP}$ is a consequence of the MC. This also accounts for the case of clefts. A cleft like It's Paul who solved the problem entails that Paul solved the problem (MC) and presupposes that someone did. The PP is thus entailed by the MC. In sum, semi-factives, win and clefts exhibit plain non-orthogonality and do not call for a special theory of ST or WT.

(47) a. I don't know if Paul participated in the race, but, if he won, he must be very proud.

b. ?? I don't know if Paul participated in the race, but if Mary participated too, they probably ran together. 


\section{Conclusion}

In this paper I have used introspective and experimental observations to show that the distinction between strong and weak triggers can be based on the interaction between the lexicon (the separation property, inspired by Abbott) and discourse planning (M-relevance) . This interaction can be expressed in a straightforward way in an elementary Bayesian framework. The (rather metaphorical) notion of (non-)orthogonality is replaced by a basic network dependency, which is more in line with a number of observations. Further experimental work, of a different nature, is needed to construct a theory of the time course and the different scenarios of activation/accommodation, in particular in the case of strong triggers. 


\section{Bibliography}

Abbott, Barbara (2006). Where are some of the presuppositions gone? In Betty J. Birner and Gregory Ward (eds.), Drawing the Boundaries of Meaning. Amsterdam: John Benjamins, pp. 1-20.

Abrusán, Márta (2011). Predicting the presuppositions of soft trigger. Linguistics and Philosophy 34, pp. 491-535.

Abusch, Dorit (2002). Lexical alternatives as a source of pragmatic presuppositions. In B. Jackson (ed.), Proceedings of Semantics and linguistic theory XII. Ithaca (NY): CLC Publications, Cornell University.

Abusch, Dorit (2010). Presupposition triggering from alternatives. Journal of Semantics 27, pp. 37-80.

Beaver, David (2001). Assertion and Presupposition in Dynamic Semantics. Stanford: CSLI Publications.

Beaver, David (2004). Have you noticed that your belly button lint colour is related to the colour of your clothing? In R. Bauerle, U. Reyle, and T. E. Zimmerman (eds.), Presuppositions and Discourse. Essays Offered to Hans Kamp. Bingley: Emerald Group Publishing Limited, pp. 65-100.

Beaver, David I. and Geurts, Bart (2013). Presupposition. In Edward N. Zalta (ed.), The Stanford Encyclopedia of Philosophy (Fall 2013 Edition). http: //plato.stanford.edu/archives/fall2013/entries/presupposition/.

Beaver, David I. and Clark, Brady Z. (2008). Sense and Sensitivity. How Focus Determines Meaning. Chichester: Wiley-Blackwell.

van Benthem, Johan, Girard, Patrick and Roy, Olivier (2009). Everything else being equal: A modal logic for ceteris paribus preferences. Journal of Philosophical Logic 38, pp. 83-125.

Chierchia, Gennaro and McConnell-Ginet, Sally (1990). Meaning and Grammar: An Introduction to Semantics. Cambridge (MA): MIT Press.

Cummins, Chris, Amaral, Patricia and Katsos, Napoleon (2013). Backgrounding and accommodation of presuppositions: an experimental approach. In Emmanuel Chemla, Vincent Homer and Grégoire Winterstein (eds.), Proceedings of Sinn und Bedeutung 1\%. http://semanticsarchive.net/sub2012/, pp. 201-218.

Ducrot, Oswald (1972). Dire et ne pas dire. Paris: Hermann.

Erteschik-Shir, Nomi (2007). Information Structure. The Syntax-Discourse Interface. Oxford: Oxford University Press.

Geurts, Bart (1995). Presupposing. Doctoral dissertation, University of Stuttgart.

Geurts, Bart (1999). Presuppositions and Pronouns. Amsterdam: Elsevier.

Geurts, Bart and Van der Sandt, Rob (2004). Interpreting focus. Theoretical Linguistics 30, pp. 1-44.

Grice, Paul (1989). Studies in the Way of Worlds. Cambridge: Harvard University Press. 
Gutzmann, Daniel (2013). Expressives and beyond. An introduction to varieties of use-conditional meaning. In Daniel Gutzmann and Hans-Martin Gärtner (eds.), Beyond Expressives: Explorations in Use-Conditional Meaning. Leiden: Brill, pp. 1-58.

Heim, Irene (1983). On the projection problem for presuppositions. In Michael Barlow, Daniel Flickinger and Michael Westcoat (eds.), Second Annual West Coast Conference on Formal Linguistics, pp. 114-126.

Horn, Laurence R. (1972). On the Semantic Properties of Logical Operators in English. UCLA Ph.D. dissertation.

Horn, Laurence R. (2001). A Natural History of Negation. Stanford: CSLI Publications.

Jayez, Jacques (2010). Projective meaning and attachment. In Maria Aloni, Harald Bastiaanse, Tikitu de Jager and Katrin Schulz (eds.), Logic, Language and Meaning. Revised Selected Papers of the 17th Amsterdam Colloquium, Amsterdam 2009, LNAI 6042. Berlin: Springer, pp. 325-334.

Jayez, Jacques and Mongelli, Valeria (2013). How hard are hard triggers? In Emmanuel Chemla, Vincent Homer and Grégoire Winterstein (eds.), Proceedings of Sinn und Bedeutung 1\%. http://semanticsarchive.net/sub2012/, pp. 307-324.

Jayez, Jacques, Mongelli, Valeria, Reboul, Anne and van der Henst, JeanBaptiste (2013). Weak and strong triggers. To appear. http://perso. ens-lyon.fr/jacques . jayez/doc/weak-strong-triggers . pdf.

Jayez, Jacques (2014). A note on presuppositions, discourse attachment and relevance. Ms. http://perso.ens-lyon.fr/jacques.jayez/doc/ Jayez-contrib.pdf. Papers in Linguistics 4, pp. 55-69.

Karttunen, Laurie (1971). Some observations on factivity. Papers in Linguistics 4, pp. 55-69.

Kauschke,Christina and Hofmeister, Christoph (2002). Early lexical development in German : a study on vocabulary growth and vocabulary composition during the second and third year of life. Journal of Child Language 29, pp. 735-757.

Kripke, Saul A. (2009). Presuppositions and anaphora: Remarks on the formulation of the projection problem. Linguistic Inquiry 40(3), pp. 367-386.

Lassiter, Daniel (2012). Presuppositions, provisos and probabilities. Semantics and Pragmatics 5(2), pp. 1-37.

Merin, Arthur (1999). Information, relevance, and social decisionmaking: Some principles and results of decision-theoretic semantics. In Lawrence S. Moss, Jonathan Ginzburg and Maarten de Rijke (eds.), Logic, Language and Computation, Vol. 2. Stanford: CSLI Publications, pp. 179-221.

Merin, Arthur (2003). Presuppositions and practical reason. A study in decisiontheoretical semantics. Forschungsberichte der DFG-Forschergruppe in der Philosophie 114, University of Konstanz.

Partee, Barbara (1991). Topic, focus and quantification. In Proceedings of SALT I, pp. 257-280.

Pearl, Judea (2009). Causality. Models, Reasoning and Inference. Cambridge: Cambridge University Press. 
Potts, Christopher (2005). The Logic of Conventional Implicature. Oxford: Oxford University Press.

Rooth, Matts (1992). A theory of focus interpretation. Natural Language Semantics 1, pp. 75-116.

Simons, Mandy (2007). Observations on embedding verbs, evidentiality, and presuppositions. Lingua 117, pp. 1034-1056.

Sletsjøe, Leif (1979). Le préfixe RE- en latin et dans les langues romanes occidentales. Studia Neophilologica 51, pp. 85-113.

Simons, Mandy, Tonhauser, Judith Beaver, David and Roberts, Craige (2011). What projects and why. In Li, Nan and Lutz, David (eds.), Semantics and linguistic theory (SALT) 20, eLanguage, 309-327.

Stalnaker, Robert (1974). Pragmatic presuppositions. In Milton K. Munitz and Peter Unger (eds.), Semantics and Philosophy. New York: New York University Press, pp. 197-214.

Zeevat, Henk (1992). Presupposition and accommodation in update semantics. Journal of Semantics 9, pp. 379-412. 